\begin{abstract}
Associate Professor Amalia CRISTESCU, PhD
E-mail: amalia.cristescu@ economie.ase.ro

The Bucharest University of Economic Studies

The National Scientific Research Institute for

Labour and Social Protection

Professor Madalina Ecaterina POPESCU, PhD

E-mail: madalina.andreica@ csie.ase.ro

The Bucharest University of Economic Studies

The National Scientific Research Institute for

Labour and Social Protection

Junior Researcher Ana-Maria GATEA

E-mail: anamaria.gatea @incsmps.ro

The National Scientific Research Institute for

Labour and Social Protection

Senior Researcher Larisa STĂNILĂ, PhD

E-mail: larisa.stanila@incsmps.ro

The National Scientific Research Institute for

Labour and Social Protection
\end{abstract}

\title{
GENDER MANAGEMENT STRATEGIES IN RESPONSE TO MINIMUM WAGE INCREASES IN ROMANIA
}

\begin{abstract}
The minimum wage policy is crucial in relaunching the economies, affecting both companies and employees. Through this paper we investigate how small and medium-sized enterprises (SMEs) react to increases in the minimum wage. We used data collected from a survey conducted in 2019 on a representative sample on Romanian companies. The effects of the minimum wage policy on SMEs, broken down by gender management types, were studied through a methodological approach that used the propensity score matching technique. The results showed that, after a minimum wage increase, female management reacts differently than male management. Female leadership mainly focuses on keeping the staffing scheme, maintaining the salary level and increasing labor productivity through innovation, while male leadership prefers to restrict salary increases or reduce bonuses or other benefits, but at the same time to increase the price of the products/services offered and to reduce non-wage costs.

Keywords: minimum wage, gender top management, wage policy, policy impact evaluation
\end{abstract}

JEL Classification: J31, M12, J16

DOI: $10.24818 / 18423264 / 55.1 .21 .06$ 


\section{Introduction}

The minimum wage policy is among the most actively debated macroeconomic policy, having various controversial implications upon the sustainability of the labor market. The main beneficiaries of minimum wage changes are low-income workers, as the policy aims to preserve their purchasing power, to increase the earnings of poor households and to motivate them to engage actively within the labor market. It also offers aid to employees of small and medium-sized enterprises (SMEs), who do not benefit from a collective labor agreement and thus cannot negotiate a salary raise. However, it is equally important to make sure that any minimum wage policy decision is evidence-based so to prevent becoming a burden for employers through increased production costs. Among companies, the wage impact is much more deeply felt in case of SMEs and, therefore, the sustainability of wage policies depends on the way the company's management reacts to the minimum wage change.

An increase in the minimum wage can lead to the risk of forming a barrier onto the labor market for low-skilled or inexperienced (young) workers, which already tend to be the category with the highest discrepancies between labor demand and supply. At the same time, if the real dynamics of productivity is below the real dynamics of labor costs, due to higher wages, companies will either pass this additional cost to consumers through goods and services sold to avoid a decrease in profit, or will adjust costs, which is less likely in the short run. In most cases, a wage increase not covered by productivity gains can generate inflationary pressures in the economy and at the same time limit the ability of firms to make new hires. In a competitive economy, the increase in labor productivity entails an increase in labor demand in the situation of unchanged earnings. Subsequently, this increase in labor demand leads to an increase in wages up until a new equilibrium is reached in which wages are equal to the marginal productivity.

Having these into consideration, this paper aims to investigate how SMEs react to minimum wage increases depending on the gender top management type. The case of Romanian SMEs is discussed. The contribution of our paper is twofold. First, a novel methodological approach is proposed to allow an impact assessment of minimum wage policy upon SMEs companies and to shed some light upon the main differences in gender top management in Romania. Our analysis was based on a survey conducted on a nationally representative sample of 1203 companies in Romania in 2019. From the total sample, only 604 companies were selected as having management staff consisting entirely of men or respectively of women in order to analyze how gender management influences the decisions on how to tackle a minimum wage increase at national level. Secondly, we bring empirical evidence to support the fact that when it comes to dealing with a change in the minimum wage policy, female top management reacts differently than men, being more focused on their employees' needs and more committed to keep their staff employed and their wage hierarchy unchanged. Eventually, these top management decisions could lead to a more sustainable labor market, since the

DOI: $10.24818 / 18423264 / 55.1 .21 .06$ 
Gender Management Strategies in Response to Minimum Wage Increases in Romania

sustainability of wage policies is directly linked to the company's management strategy to tackle minimum wage adjustments. Obviously, any increase in the level of the minimum wage has an impact on companies, but the size of this impact also depends on how the company's management handles such situations.

The paper is structured as follows: Section 2 is dedicated to the literature review in the field. The data sample and the methodology are described in Section 3 , while the main results of the impact evaluation analysis of the minimum wage changes upon SMEs companies, broken down by gender management types, are presented in Section 4. The last section is dedicated to the discussions and the concluding remarks of the paper.

\section{Literature review}

Several studies have focused on how SMEs react to minimum wage adjustments, in general, and on the main differences in male versus female top management, in particular. However, empirical studies linking the two aspects together are rather scarce. For instance, Parrotta and Smith (2013) investigated the relationship between CEO gender and firm's risk attitude, measured through changes in some company's financial indicators (investments, profitability and wages). Using survey data on Danish companies with more than 50 employees, the authors found a negative association between the female CEO and the company's risk attitudes. This result supports some theoretical assumptions that women typically have a substantially higher risk aversion profile and would put more effort into monitoring the company's activities than men.

Magda and Cukrowska-Torzewska (2018) analyzed the link between the presence of female managers and the pay gap between women and men in the private and public sector companies in Poland. Using survey data from the Structure of earnings and wages database, the authors found no link between female managers and significant gender pay-gap in the private sector. They showed that a higher share of female workers is correlated with a smaller wage gap, especially in private companies that employ a large number of low-skilled workers. In the public sector, however, there are some institutions with women managers and some gender pay gaps in favor of women, especially in public administration and education, where higher salaries are paid and where a high qualification is required.

Gagliarducci and Paserman (2014) investigated how gender top management in German companies affects the results of companies and employees using annual survey data. The results showed that there is a strong negative association between the share of women in senior management and a number of economic and financial indicators of the company, such as turnover, investments, total salary per worker and total employment. At the same time, companies with a higher share of women in management staff are willing to implement more femalefriendly policies, such as providing childcare facilities or promoting and guiding

DOI: $10.24818 / 18423264 / 55.1 .21 .06$ 
young employees, while also dealing with the reservation wage level (Vasilescu and Begu, 2019).

However, Amore et al. (2014) showed that female directors of firms in Italy significantly improve the operating profitability of companies. The methods used in the analysis were the propensity score matching (PSM) and the instrumental variables methods. To test the company's profitability before and after the transition from male to female management, they used a control sample of firms that had a transition from male to male management. The authors used a matching procedure for a better isolation of changes in companies' profitability and salaries before the change of management in order to be able to compare the results of the transition from male to male with those from male to female management. The results also showed that the positive effect of female interactions on profitability is reduced when the firm is located in geographical areas characterized by gender bias and when the firm is large.

Moreover, Flabbi et al. (2014) analyzed the impact of female management on Italian companies, using annual survey data, and found that female executives make a difference: the interaction between female management and women working in the company has a significant positive impact on the company's performance. At the same time, women's leadership involves lower wages for women at the top of the payroll and higher wages for women at the bottom of wages. Practically, this evidence is consistent with a model of statistical discrimination in which female directors correct the discrimination generated by male directors. The results also indicated that there are productivity costs associated with the low representation of women in business management.

In another study, Dezso and Ross (2011) investigated the gender differences in management for 1,500 companies listed on US stock exchanges. They found that the representation of women in top management improves the performance of companies and determines a salary growth, but only insofar as the main strategy of the company is focused on innovation. This is because the informational and social benefits of gender diversity and the behavior associated to women managers are probably particularly important for the optimal performance of the managerial tasks. Women managers are more willing to increase salaries compared to men and are also more open to innovation, motivating middle female management to act through measures to increase the company's performance for further promotion.

Regarding the impact of minimum wage on wage distribution, there is empirical proof to support that, in developing countries, the minimum wage has a greater potential to shape wage distribution than in developed countries (Rani and Ranjbar, 2015). In the medium and long run, if firms fail to cover the increase in the minimum wage through increased productivity, investments in innovation or price increases without affecting competitiveness, then the effects will be seen in a decrease in labor demand and, implicitly, in a drop of employment, as well as in a decrease of the firms' development opportunities (Aaronson et al., 2016).

DOI: $10.24818 / 18423264 / 55.1 .21 .06$ 
Gender Management Strategies in Response to Minimum Wage Increases in Romania

In the context of emerging economies, as is the case of Romania, a majorly raising wages may increase the risk of economic overheating. From this perspective, the study and evaluation of wage policies represents a priority for Romania. For instance, The National Romanian Council for Small and Medium Private Enterprises (CNIPMMR, 2018) conducted an online survey in 2018 on a number of 963 Romanian companies and stressed that a vast majority of the respondents feel that a minimum wage increase would pose difficulties for businesses. On the other hand, an increase of the minimum wage would predominantly lead to: dismissal of employees, lowering competitiveness, rising prices for goods and services, losing contracts/markets or decreasing profits. At the same time, the survey reveals that $67 \%$ of respondents have stressed the necessity for a rigorous grounding of the minimum wage on objective criteria, while $62 \%$ asked for impact studies.

Recently, Popescu et al. (2017) conducted such an impact study on the effects of the minimum wage policy upon employment, earnings and income inequalities in Romania, in order to build a national minimum wage setting mechanism. They identified some relevant socio-economic factors that can be used in analyzing the minimum wage policy, by making a distinction between impact evaluation indicators and criteria indicators for setting up the minimum wage level.

\section{Data and methodology}

\subsection{Data sample}

In order to study the behavior of Romanian companies towards wage policies, a statistical survey was conducted on a nationally representative sample of companies. The sample included companies from all regions of the country, both urban and rural areas. A stratified sample was used as a sampling method, as stratified samples that respect the structure of the population from which they are extracted are considered to be more robust and lead to an even lower sampling error than that calculated for simple random samples. The stratification criteria were: size of the enterprise (less than 9 employees; between 10-49 employees; between 50-249 employees; over 250 employees), county/development region, main field of activity of the enterprise and level of turnover. The sample's statistical margin error was $+/-3 \%$. The data collection was performed during October - November 2019 through a mixed of methods: CAWI (Computer Aided Web Interview), CATI (Computer-assisted personal interview) and Face-to-Face. The collected data were processed in STATA software.

The total volume of questionnaires obtained was of 1203 . The structure by fields of activity indicated that $28.8 \%$ of the companies participating in the survey were from the field of Trade, $14.4 \%$ from Professional scientific and technical activities, $11.4 \%$ from Industry, $10.6 \%$ from Constructions, $7.6 \%$ of Transport and storage, and the rest of the fields were less than $5 \%$ representative.

In view of the investigation aimed by this paper, we reduced the sample size only to the companies for which the top management staff was composed

DOI: 10.24818/18423264/55.1.21.06 
entirely of men, respectively entirely of women. Under these conditions, the number of questionnaires decreased to 604 companies. The distribution on area of residence showed that both in urban and rural areas over half of the companies have full management staff consisting of women (59\% in rural areas and 57\% in urban areas).

Of the companies that stated that they have people employed at the level of the minimum wage, a significant majority (91\%) have between 1 and 10 employees paid by the minimum wage. Of this majority, $67 \%$ of companies have full management staff consisting of women.

The representation at the regional level indicated that there is a relatively balanced distribution among the eight economic development regions. Except for the capital region Bucharest - Ilfov, in all the other regions the companies with management staff consisting entirely of women are in majority. In the BucharestIlfov region, the percentage of companies that have full male management staff is $54 \%$. The highest percentages of companies with management staff consisting entirely of women are registered in the Central (72\%), South-West (68.6\%) and North-East $(64.3 \%)$ regions. The high share of women in managerial positions is also justified by the small size of the companies included in the sample (over $90 \%$ of them have less than 9 employees) as it is considered that the lower the size of the company, the easier women gain managerial position (Amore, 2014).

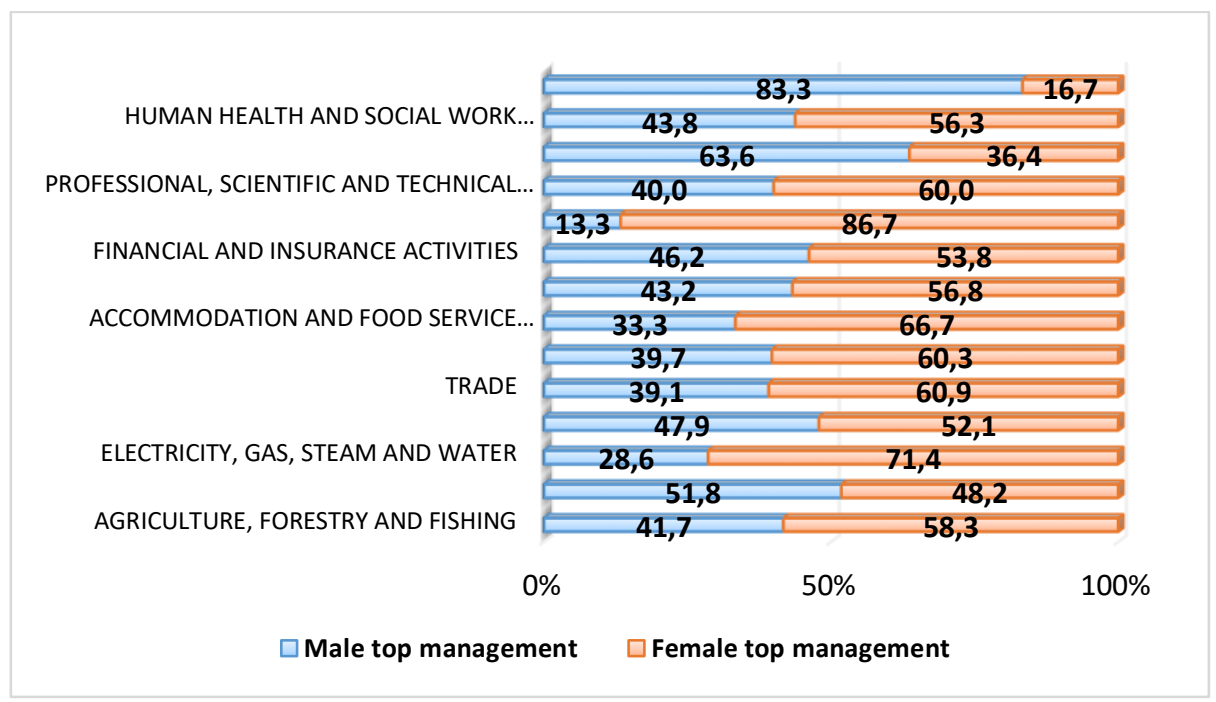

Source: own calculations based on survey data

Figure 1. Structure by activity fields according to top management type

The structure by economic sectors indicates that women are involved in leadership in all areas, from Information and Communications, to Agriculture and Energy, trying to strike a balance. The highest percentage of women in

DOI: $10.24818 / 18423264 / 55.1 .21 .06$ 
Gender Management Strategies in Response to Minimum Wage Increases in Romania

management is observed in companies in the field of Real Estate Transactions $(86.7 \%)$.

High percentages are also observed in the fields of Electricity and Heat, Gas and Water (71.4\%), Hotels and Restaurants (66.7\%), Trade (60.9\%) and Transport and Storage $(60.3 \%)$. The fields with the lowest management staff consisting entirely of women are Entertainment, cultural and recreational activities (16.7\%), Education (36.4\%) and Industry (48.3\%).

\subsection{Methodology of investigation}

In this paper, a novel methodological approach is proposed to evaluate the impact of a minimum wage adjustment upon SMEs companies, broken down by gender management types. Even though we did not have access to each company's employees microdata in order to build a proper counterfactual scenario, we surveyed the companies top managers about the changes that took place right after the latest increase of the minimum wage (from 1450 Ron to 1900 Ron) in January 2018.

The impact of the minimum wage policy was estimated on four distinct dimensions, regarding changes in the companies wage policy, personnel fluctuations, changes in labor productivity, as well as changes in prices of final goods/services or non-wage costs.

At company level, the changes in personnel were investigated not only through the annual growth rate in the total number of employees registered in 2018 as compared to the previous year, but also through top managers' decisions to reduce the staffing scheme or the number of new jobs created, as well as to replace existing employees with new ones on lower salaries in order to tackle the minimum wage increase. Moreover, the top managers were also asked to estimate the chances for the new minimum wage level to become an impediment in hiring young people in their own companies.

Regarding the changes in company's wage policy, the top managers were asked about the share of employees right above minimum wage level that also benefited from a wage increase after the minimum wage rise and about any management decision to restrict salary increases or to reduce bonuses, other employees benefits or pension contributions.

In terms of labor productivity, we computed the annual growth rate of labor productivity in 2018 as compared to the previous year, by considering the ratio between turnover and number of employees. However, we also investigated the top management decisions upon increasing labor productivity through innovation or upon reducing the number of working hours/overtime when dealing with the latest minimum wage increase.

Finally, we also evaluated how the companies' prices of final products or services were affected by the minimum wage change and checked whether other costs except labor ones had to be reduced in order to better cope with the current situation.

DOI: 10.24818/18423264/55.1.21.06 
The effects of the minimum wage policy upon SMEs companies were then broken down by gender management type. Instead of using simple mean comparisons between companies run entirely by women versus those run entirely by men for all those 12 aspects considered for the minimum wage impact evaluation we propose a novel methodological approach based on the use of the propensity score matching technique. The basic idea of the PSM method adjusted to this study consists in building two distinct company groups, that are similar in observable characteristics, but have the difference that one group is made up entirely by firms with male top management and a control group made up by firms with female managers.

When applying the PSM method, we used the psmatch2 command in STATA 16 and the following observable characteristics: the company's size (less than 9 employees; between 10-49 employees; between 50-249 employees; over 250 employees), the economic development region, the main field of activity of the company and the levels of turnover and profit registered in the latest available year. Dummy variables were created for each specific characteristics, with a particular approach when dealing with financial indicators, for which four distinct dummy variables were created corresponding to the four quartiles of the distribution.

When checking for differences in structure of both the treated and the control group based on observable characteristics using the Student t-test for mean differences (see Table 1) we found some rather significant differences between the two groups, especially in terms of financial and economic activity. Since the two groups do not properly reflect similar background information, we concluded that it is necessary to apply a matching procedure.

Table 1. Descriptive statistics and mean differences between the treatment and the control group

\begin{tabular}{|c|c|c|c|c|c|c|}
\hline \multirow[b]{2}{*}{ Covariates } & \multicolumn{2}{|c|}{ Treated group } & \multicolumn{2}{|c|}{ Control group } & \multicolumn{2}{|c|}{ Differences between groups } \\
\hline & Mean & $\begin{array}{l}\text { Std. } \\
\text { dev. }\end{array}$ & Mean & $\begin{array}{l}\text { Std. } \\
\text { dev. }\end{array}$ & Diff. & Mean diff. \\
\hline $\begin{array}{l}\text { Bucharest-Ilfov } \\
\text { region }\end{array}$ & 0.32 & 0.47 & 0.2 & 0.4 & -0.12 & Ha: diff $!=0 \operatorname{Pr}(|\mathrm{T}|>|\mathrm{t}|)=0.00$ \\
\hline Centre region & 0.08 & 0.27 & 0.16 & 0.36 & 0.07 & Ha: diff $!=0 \quad \operatorname{Pr}(|T|>|t|)=0.00$ \\
\hline $\begin{array}{l}\text { South-West } \\
\text { region }\end{array}$ & 0.04 & 0.2 & 0.07 & 0.25 & 0.03 & Ha: diff $!=0 \operatorname{Pr}(|\mathrm{T}|>|\mathrm{t}|)=0.15$ \\
\hline North-East region & 0.12 & 0.32 & 0.16 & 0.36 & 0.04 & Ha: diff $!=0 \quad \operatorname{Pr}(|T|>|t|)=0.16$ \\
\hline $\begin{array}{l}\text { North-West } \\
\text { region }\end{array}$ & 0.14 & 0.35 & 0.16 & 0.36 & 0.01 & Ha: diff $!=0 \quad \operatorname{Pr}(|\mathrm{T}|>|t|)=0.69$ \\
\hline South region & 0.1 & 0.3 & 0.08 & 0.27 & -0.02 & Ha: diff $!=0 \quad \operatorname{Pr}(|\mathrm{T}|>|t|)=0.39$ \\
\hline South-East region & 0.12 & 0.32 & 0.11 & 0.31 & -0.01 & Ha: diff $!=0 \quad \operatorname{Pr}(|\mathrm{T}|>|\mathrm{t}|)=0.78$ \\
\hline $\begin{array}{l}\text { Less than } 10 \\
\text { employees }\end{array}$ & 0.92 & 0.27 & 0.94 & 0.24 & 0.02 & Ha: diff $!=0 \quad \operatorname{Pr}(|\mathrm{T}|>|\mathrm{t}|)=0.39$ \\
\hline 10-49 employees & 0.08 & 0.27 & 0.05 & 0.22 & -0.03 & Ha: diff $!=0 \quad \operatorname{Pr}(|\mathrm{T}|>|t|)=0.11$ \\
\hline Turnover_Q1 & 0.58 & 0.5 & 0.31 & 0.46 & -0.27 & Ha: diff $!=0 \quad \operatorname{Pr}(|\mathrm{T}|>|\mathrm{t}|)=0.00$ \\
\hline Turnover_Q2 & 0.23 & 0.42 & 0.37 & 0.48 & 0.14 & Ha: diff $!=0 \quad \operatorname{Pr}(|\mathrm{T}|>|\mathrm{t}|)=0.00$ \\
\hline Turnover_Q3 & 0.11 & 0.31 & 0.21 & 0.41 & 0.10 & Ha: diff $!=0 \quad \operatorname{Pr}(|\mathrm{T}|>|t|)=0.00$ \\
\hline
\end{tabular}

DOI: $10.24818 / 18423264 / 55.1 .21 .06$ 
Gender Management Strategies in Response to Minimum Wage Increases in Romania

\begin{tabular}{ccccccc}
\hline Turnover_Q4 & 0.09 & 0.28 & 0.11 & 0.31 & 0.03 & Ha: diff $!=0 \operatorname{Pr}(|\mathrm{T}|>|\mathrm{t}|)=0.27$ \\
Profit_Q1 & 0.41 & 0.49 & 0.29 & 0.45 & -0.12 & Ha: diff $!=0 \operatorname{Pr}(|\mathrm{T}|>|\mathrm{t}|)=0.00$ \\
Profit_Q2 & 0.27 & 0.44 & 0.33 & 0.47 & 0.06 & Ha: diff $!=0 \operatorname{Pr}(|\mathrm{T}|>|\mathrm{t}|)=0.10$ \\
Profit_Q3 & 0.18 & 0.39 & 0.24 & 0.42 & 0.06 & Ha: diff $!=0 \operatorname{Pr}(|\mathrm{T}|>|\mathrm{t}|)=0.07$ \\
Profit_Q4 & 0.14 & 0.35 & 0.144 & 0.35 & 0.00 & Ha: diff $!=0 \operatorname{Pr}(|\mathrm{T}|>|\mathrm{t}|)=0.88$ \\
Industry sector & 0.12 & 0.32 & 0.09 & 0.29 & -0.03 & Ha: diff $!=0 \operatorname{Pr}(|\mathrm{T}|>|\mathrm{t}|)=0.27$ \\
Trade sector & 0.25 & 0.43 & 0.28 & 0.45 & 0.04 & Ha: diff $!=0 \operatorname{Pr}(|\mathrm{T}|>|\mathrm{t}|)=0.30$ \\
Private services & 0.37 & 0.48 & 0.43 & 0.49 & 0.06 & Ha: diff $!=0 \operatorname{Pr}(|\mathrm{T}|>|\mathrm{t}|)=0.12$ \\
Public services & 0.09 & 0.29 & 0.04 & 0.2 & -0.05 & Ha: diff $!=0 \operatorname{Pr}(|\mathrm{T}|>|\mathrm{t}|)=0.02$ \\
Construction & 0.13 & 0.34 & 0.11 & 0.31 & -0.03 & Ha: diff $!=0 \operatorname{Pr}(|\mathrm{T}|>|\mathrm{t}|)=0.34$ \\
sector & & & &
\end{tabular}

Sources: authors' own calculations based on survey data

The PSM method is a two-step semi-parametric estimation, consisting first in an estimation of a binary model (such as a logit or a probit model), followed by a non-parametric comparison between the previously estimated propensity scores. In this case, we have opted for a probit model, which has the following general form:

$\operatorname{Pr}\left(T_{i}=1 \mid X_{i}\right)=\int_{-\infty}^{X_{i}} \varphi(t) d t=\varphi\left(X_{i}\right)$

where $X_{\mathrm{i}}$ represent the observable characteristics of the companies presented above in Table $1, T_{i}$ is the treatment variable that takes value 1 in case companies are run entirely by men and 0 in case of women, while $\varphi\left(X_{i}\right)$ is the normal density function, which has the following form:

$$
\varphi\left(X_{i}\right)=\frac{\exp \left(-\frac{X_{i}{ }^{2}}{2}\right)}{\sqrt{2 \pi}}
$$

The observed value of the outcome for each unit can be written as: $Y_{i}=$ $\mathrm{T}_{\mathrm{i}} \mathrm{Y}_{\mathrm{i}}(1)+\left(1-\mathrm{T}_{\mathrm{i}}\right) \mathrm{Y}_{\mathrm{i}}(0)$, where $\mathrm{Y}_{\mathrm{i}}(1)$ represents the outcome of a company $i$ run by men and $\mathrm{Y}_{\mathrm{i}}(0)$ stands for the outcome in case company $i$ is run by women. The treatment effect is given by the difference $T E_{i}=Y_{i}(1)-Y_{i}(0)$.

After determining the propensity scores $\mathrm{p}\left(\mathrm{X}_{\mathrm{i}}\right)$, the companies run by men are matched with the companies run by women according to their scores, using a matching algorithm. Among the most commonly used matching algorithms, for this study we selected the Nearest-Neighbour $(\mathrm{NN})$, the Caliper and the Radius Matching algorithms. The NN algorithm identifies for each company with male managers the comparison company run by women managers that has the closest propensity score. According to Dehejia anf Wahba (1998) the simplest metric distance for seeking the nearest match can be computed as follows:

$$
d(i, J)=\left|p\left(X_{i}\right)-\frac{1}{J} \sum_{j \in J} p\left(X_{j}\right)\right|
$$

DOI: 10.24818/18423264/55.1.21.06 
where $\mathrm{p}\left(\mathrm{X}_{\mathrm{i}}\right)$ stands for the probability of company $i$ to be run only by men, while $J$ is a set of control companies that are run by women $(|J|$ denotes the cardinality of $J)$.

However, the NN algorithm could still face the risk of poor matches, since it implies a trade-off between variance and bias. One way to solve such problem consists in using a caliper or a radius, which could allow for a maximum level tolerance of the propensity score distances, even though estimating a reasonable tolerance level could be rather challenging (Dehejia and Wahba, 2002).

Since a matching algorithm is applied to find for each company run by men a similar one run by women based on observable data, this technique has the benefit to reduce the bias in the treatment effects estimation. The impact of the minimum wage policy was then estimated as the difference between the effect registered at the company run by men and the matched comparison one run by women. Finally, when averaging across all companies we determine the average impact of the minimum wage policy upon the entire company sample. This approach will allow us to shed some light upon the main differences in gender topmanagement in Romania when dealing with a minimum wage change at national level.

\section{Main results}

When having a first glance at the main responses provided by the top managers of the surveyed companies sample, we notice that in the event of an increase in the minimum wage, companies adopt a series of measures, most of which tending to support their employees. When being asked whether the company's management is in favor of increasing all wages proportionally when a rise in the minimum wage occurs, a vast majority of $74 \%$ among all companies run by men declared to adopt such measure, as compared to $71 \%$ of all companies with female top management.

The differences between gender top management are a little bit lower, however, in the case of companies where just the employees right above minimum wage and those at the minimum wage would be considered to benefit from a wage adjustment once the minimum wage increases. In this case, there are only $10 \%$ of all companies run by men to adopt such internal wage policy and just $8 \%$ out of all the companies with female management. On the other hand, the most risk adverse internal wage policy consists in the case when only minimum wage employees benefit from a wage adjustment when minimum wage increases. In this situation there are about $16 \%$ of all companies run by men that would consider such internal wage policy, but about $21 \%$ out of all companies run entirely by women. These results support some theories that female management shows a more pronounced aversion to risk compared to male management (see also Parrotta et al., 2013). Basically, the female management is more cautious when dealing with a minimum wage increase at national level, having a more robust internal wage policy as compared to male managers, so as not to affect the financial situation of the company.

DOI: $10.24818 / 18423264 / 55.1 .21 .06$ 
Gender Management Strategies in Response to Minimum Wage Increases in Romania

For a much thorough investigation of the main particularities between female and male top managements, we have applied a propensity score matching analysis that allowed us to reduce the bias when comparing the minimum wage impact on the Romanian SMEs. Several probit models were tested for validity and ability to explain the main differences between male and female top management. The following final probit model was obtained using as covariates the observable characteristics described in the methodology section and as dependent variable the gender top management type (which is a binary variable that takes value 1 in case the companies are run entirely by men and 0 in case they are run entirely by women) (see Table 2). We first notice that not all explanatory variables were kept in the final model as turning out to be less relevant in capturing the differences between male and female management.

Table 2. The econometric results of the probit model

\begin{tabular}{lllc}
\hline \multicolumn{1}{c}{ Covariates } & Coeff. & $\begin{array}{l}\text { Std. } \\
\text { errors }\end{array}$ & Z test \\
\hline Bucharest-Ilfov region & $0.129^{* * *}$ & 0.050 & 2.560 \\
Center region & $-0.148^{* *}$ & 0.062 & -2.250 \\
South-West region & $-0.142^{*}$ & 0.082 & -1.610 \\
Turnover_Q1 & $0.332^{* * *}$ & 0.056 & 5.610 \\
Turnover_Q2 & 0.047 & 0.063 & 0.750 \\
Profit_Q4 & $0.141^{* *}$ & 0.070 & 1.990 \\
Constructions sector & 0.064 & 0.066 & 0.970 \\
No. obs. $=599$ & LR chi2=66.46 & & Log \\
Pseudo $R^{2}=0.08$ & P value $=0.00$ & & likelihood $=-375.9$ \\
\hline
\end{tabular}

where ${ }^{* * * *},{ }^{* *},{ }^{*}$ stand for $1 \%, 5 \%$ and respectively $10 \%$ significance level.

Sources: authors' own calculations based on survey data

In terms of validity of the probit model, even though the pseudo R squared reaches a very modest level of $8 \%$, indicating that more explanatory variables are required to improve the representativity of this model, we accept such biases, due to current data limitations and conclude that the model is statistically significant according to the LR test. The utility of the model is, however, twofold. On the one hand, the propensity scores for each company are generated in order to be later used in a matching algorithm. On the other hand, it brings some inputs for profiling the companies with male top management in contrast to female management based on observable characteristics. Thus, based on the variables with statistically significant coefficients we could say that, in general, companies run entirely by men are more profitable and have more chances to activate in the Bucharest-Ilfov region, but lower chances to activate in the Centre or in the South-West regions

DOI: $10.24818 / 18423264 / 55.1 .21 .06$ 
than companies run by women. This comes as no surprise, since the BucharestIlfov region hosts the capital of Romania, where higher economic dynamic is expected due to more profitable business opportunities and available skilled labor force supply. Having such economic advantages could help the SMEs activating in this region boost their productivity and profitability.

The results that were statistically significant after applying the PSM technique using NN, Radius and caliper matching algorithms are summarized in Table 3, where the ATT column represents the average treatment effect on the treated (ATT). This estimator indicates the impact of the minimum wage policy after computing the differences between the mean performances of the two groups matched. The T-statistic values are summarized in the last column of Table 3.

Among the 12 elements investigated through this paper in terms of minimum wage policy impact upon SMEs, only the ATT corresponding to the management decision to replace existing employees with new ones on lower salaries turned out to be statistically insignificant. Based on the other investigated aspects we were, however, able to bring empirical evidence to support the fact that when dealing with a minimum wage change, female top management reacts differently than men, being more focused on their employees' needs and more committed to keep their staff employed and their wage hierarchy unchanged.

For instance, in terms of personnel changes affected by a rise in the minimum wage, companies with male top management had a lower annual growth rate in the total number of employees in 2018 by $19.3 \%$ in comparison to similar companies run by women.

Table 3. Minimum wage impact evaluation upon SMEs in 2018 vs. 2017

\begin{tabular}{|c|c|c|c|c|c|}
\hline $\begin{array}{c}\text { Impact } \\
\text { dimension }\end{array}$ & $\begin{array}{l}\text { Effects of minimum wage } \\
\text { increase at company level }\end{array}$ & $\begin{array}{c}\text { Treatment } \\
\text { group (Male } \\
\text { management) }\end{array}$ & $\begin{array}{c}\text { Control } \\
\text { group } \\
\text { (Female } \\
\text { management) }\end{array}$ & ATT & $\begin{array}{c}\text { T- } \\
\text { statistic }\end{array}$ \\
\hline \multirow[t]{2}{*}{$\begin{array}{l}\text { Changes in } \\
\text { firm's wage } \\
\text { policy }\end{array}$} & $\begin{array}{l}\text { Share of employees right } \\
\text { above minimum wage level } \\
\text { that benefited from a wage } \\
\text { increase }\end{array}$ & $21.6 \%$ & $30.1 \%$ & $-8.5 \%$ & -2.4 \\
\hline & $\begin{array}{l}\text { Restricted wage increases } \\
\text { or reduced bonuses, other } \\
\text { employees benefits or } \\
\text { pension contributions }\end{array}$ & $47 \%$ & $23 \%$ & $24 \%$ & 5.9 \\
\hline \multirow{4}{*}{$\begin{array}{l}\text { Personnel } \\
\text { changes }\end{array}$} & Reduced staffing scheme & $52 \%$ & $37 \%$ & $15 \%$ & 3.5 \\
\hline & Fewer new jobs created & $8 \%$ & $15 \%$ & $-7 \%$ & 1.9 \\
\hline & $\begin{array}{l}\text { The annual growth rate in } \\
\text { total number of employees }\end{array}$ & $-11.4 \%$ & $7.9 \%$ & $-19.3 \%$ & 3.0 \\
\hline & $\begin{array}{l}\text { Chances that the new } \\
\text { minimum wage level has } \\
\text { become an impediment to } \\
\text { hire young people }\end{array}$ & $15 \%$ & $8 \%$ & $8 \%$ & 2.5 \\
\hline
\end{tabular}


Gender Management Strategies in Response to Minimum Wage Increases in Romania

\begin{tabular}{|c|c|c|c|c|c|}
\hline \multirow{2}{*}{$\begin{array}{l}\text { Changes in } \\
\text { other costs } \\
\text { and prices }\end{array}$} & $\begin{array}{l}\text { Increased prices } \\
\text { products/services }\end{array}$ & $33 \%$ & $25 \%$ & $8 \%$ & 1.9 \\
\hline & Reduced non-wage costs & $29 \%$ & $21 \%$ & $8 \%$ & 2.2 \\
\hline \multirow[t]{3}{*}{$\begin{array}{l}\text { Changes in } \\
\text { labor } \\
\text { productivity }\end{array}$} & $\begin{array}{lr}\begin{array}{l}\text { Increased } \\
\text { productivity }\end{array} & \text { labor } \\
\text { innovation } & \text { through }\end{array}$ & $7 \%$ & $15 \%$ & $-7 \%$ & 2.7 \\
\hline & $\begin{array}{l}\text { Reduction in the number of } \\
\text { working hours/overtime }\end{array}$ & $52 \%$ & $18 \%$ & $34 \%$ & 8.6 \\
\hline & $\begin{array}{l}\text { The annual growth rate of } \\
\text { labor productivity }\end{array}$ & $50 \%$ & $14 \%$ & $36 \%$ & 2.2 \\
\hline
\end{tabular}

Actually, the companies run by men registered in 2018 a drop by $11.4 \%$ in the total number of employees, while on the opposite side, similar companies with female top management registered an increase of $7.9 \%$ in the same year. Moreover, one can observe that male top managers' decisions to reduce the staffing scheme because of the minimum wage increase were more drastic in comparison to female top management. More precisely, companies run by men have $15 \%$ more chances to reduce their staffing scheme than similar companies run by women when dealing with a minimum wage adjustment. These results suggest that female managers tend to place more value on their current employees when dealing with financial difficulties and focus more on keeping their human resource structure intact. However, they seem to be more reserved when deciding upon creating new job opportunities inside their companies after a minimum wage change, having $7 \%$ higher chances than men managers to reduce the total number of new jobs created under a minimum wage adjustment.

When evaluating just how hard the minimum wage change could affect their company's chances to hire young people, female managers seem to be more open and motivated to hire them, estimating lower chances by $8 \%$ than male managers to consider the new minimum wage level as an impediment in recruiting new young staff.

Regarding the changes in company's wage policy generated by the latest minimum wage increase, companies with male managers turned out to have a lower share of employees right above minimum wage level who also benefited from a wage adjustment after the minimum wage rise, these companies having with $8.5 \%$ lower chances than companies with female managers to apply such internal wage policy.

This particular finding is to some degree in contrast with our previous observations when using simple mean comparisons between companies run entirely by women versus those run entirely by men, suggesting that without a matching technique, the conclusions could be biased unless the sample is uniformly structured within groups.

In terms of management decisions to restrict salary increases or to reduce bonuses, other employees' benefits or pension contributions, male managers tend

DOI: $10.24818 / 18423264 / 55.1 .21 .06$ 
to be more rigid and profit-focused, having $24 \%$ higher chances than female managers to apply such internal wage policy in order to tackle the rise in the minimum wage.

Regarding labor productivity, the minimum wage adjustment could have a higher negative impact on the companies run by women in comparison to similar companies run by men, leading to a reduction by $36 \%$ in the labor productivity in 2018 as compared to the previous year. However, our findings suggest that the minimum wage increase contributed more upon female managers to motivate them to increase their labor productivity through innovation. In comparison to companies run by female managers, similar companies with men CEOs had $7 \%$ less chances in increasing their productivity in the year 2018 through innovation. However, these companies had $34 \%$ more chances in reducing the number of working hours/overtime when dealing with the latest minimum wage increase than companies with female managers. This could also explain the more significant rise registered in 2018 in the labor productivity, in comparison to companies run by female managers.

Finally, when evaluating how the companies prices of final products or services or other costs except labor ones were affected by the minimum wage change, we notice that male managers are $8 \%$ more likely to decide upon increasing prices or upon cutting other costs down than those related to labor force in comparison to female managers of similar companies.

\section{Conclusions}

Our paper has investigated the impact of minimum wage policy upon SMEs companies in Romania and the differences in companies' top management in tackling such a policy change. Through our study, we were able to bring empirical evidence to support the fact that when it comes to dealing with a change in the minimum wage policy, female top management reacts differently than men, being more focused on their employees' needs and more committed to keeping their staff employed and their wage hierarchy unchanged. At the same time, the female management is more open and motivated to hire young people, not considering the minimum wage an impediment in recruiting young employees. On the other hand, men managers prefer to reduce the staffing scheme and the number of working hours/overtime when faced with the latest increase in the minimum wage. Moreover, male managers seem to be more profit-oriented, indicating that their decisions are to restrict wage increases or to reduce bonuses or other employee benefits, and at the same time to increase the price of products/services offered and to reduce non-wage costs. The female management is the follower of innovation, even if it means additional investment, while male management focus more on increasing productivity and prices of products/services offered on the market. These aspects could also explain the more significant increase registered in 2018 in terms of labor productivity of companies run by men compared to those run by women. 
Gender Management Strategies in Response to Minimum Wage Increases in Romania

These results cannot make us state with certainty that a management type can lead to a higher sustainability at the company level. The analysis showed that male management is more pragmatic, adopts more drastic measures with shortterm visible effects, while female management has a less drastic perspective by adopting measures with effects that can be seen in the medium and long term. The results of this analysis may be useful for wage and income policy makers because they can anticipate the effects of an increase in the minimum wage depending on gender management, especially since it is known that in certain economic sectors male managers predominate (Agriculture, Industry, Construction), and in other sectors, female managers (Trade, Hotels and restaurants, Real estate transactions). Basically, managers' reactions are useful to see how minimum wage increases are transposed into the economic and social environment - through measures related to changes in company's salaries, staff, production costs, sales prices and labor productivity.

Keeping in mind the data limitations of the collected survey data, we are aware that microdata on company's employees would have been ideal to allow for a more robust estimation of the minimum wage impact upon SMEs through a proper counterfactual impact analysis. However, we believe that through surveying the companies' top managers about the changes that took place right after the latest increase of the minimum wage in 2018 in Romania, and through a thorough data analysis, we were able to bring empirical evidence on how SMEs were affected by such a change at national level. Moreover, since studies investigating how SMEs react to minimum wage adjustments while also focusing on the main differences in male versus female top-management are rather scarce, we believe to have filled this gap, by bringing empirically based evidences for the case of an emerging country.

As a conclusion, we can state that the measures adopted by companies in response to the minimum wage increase differ depending on the gender management type. Obviously, the measures adopted can also influence the economic and financial indicators of the companies in the short and medium term. Thus, we could say that the female management adopts measures trying to protect the company's existing employees and avoids more to reduce salaries or to create new jobs, while relying on an increase in productivity through innovation. Male management takes measures to reduce the staffing scheme, reduce salaries or bonuses, but at the same time compensates the expenses by increasing the price of products/services offered and by reducing other non-wage costs. In a metaphorical conclusion, we could even say that male management is more pragmatic, while female management is more sentimental.

ACKNOWLEDGMENTS

Part of this work was supported by the NUCLEU Program funded by the Romanian Ministry of Research and Innovation (Project PN 19130103).

DOI: 10.24818/18423264/55.1.21.06 
Amalia Cristescu, Madalina Ecaterina Popescu, Ana-Maria Gatea, Larisa Stanila

\section{REFERENCES}

[1] Aaronson, D., French, E., Sorkin, I. (2016), The Long Run Employment Effects of the Minimum Wage: A Putty Clay Perspective. VOXeu, CEPR's Portal.https://voxeu.org/article/long-run-employment-effects-minimum-wage;

[2] Amore M. D., Garofalo O., Minichilli A. (2014), Gender Interactions within the Family Firm. Management Science, Vol. 60 (5): 1083-1097;

[3] Consiliul Naţional al Întreprinderilor Private Mici şi Mijlocii din România (CNIPMMR) (2018), Testul IMM privind cresterea salariului minim pe economie de la 1.900 lei la 2.080 lei si la 2.350 lei. https://cnipmmr.ro/2018/11/26/testul-imm-privind-cresterea-salariului-minimpe-economie-de-la-1-900-lei-la-2-080-lei-si-la-2-350-lei/ ;

[4] Dehejia, R.H., Wahba, S. (2002), Propensity Score Matching Methods for Non-Experimental Causal Studies. Columbia University, Department of Economics Discussion Paper Series, Discussion Paper 0102-14;

[5] Dezso, C.L., Ross, D.G. (2011), Does Female Representation in Top Management Improve Firm Performance? A Panel Data Investigation. Strategic Management Journal, 33(9), DOI: 10.2307/23261318;

[6] Flabbi, L., Macis, M., Moro, A., Schivardi, F. (2014), Do Female Executives Make a Difference? The Impact of Female Leadership on Firm Performance and Gender Gaps in Wages and Promotions; https://pdfs.semanticscholar.org/af20/6a765aae003bfb472d45952e05051d5cd 6e1.pdf?_ga=2.13996599.1694568206.1589308270-1683904422.1584879000

[7] Gagliarducci, S., Paserman, M.D. (2014), The Effect of Female Leadership on Establishment and Employee Outcomes: Evidence from Linked Employer-Employee Data. IZA Discussion Paper, 8647;

[8] Magda, I., Cukrowska-Torzewska, E. (2018), Do Female Managers Help to Lower within-Firm Gender Pay Gaps? Public Institutions vs. Private Enterprises. IZA Discussion Paper, 12026, http://ftp.iza.org/dp12026.pdf ;

[9] Parrotta P., Smith, N. (2013), Female-Led Firms: Performance and Risk Attitudes. IZA Discussion Paper, 7613, http://anon-ftp.iza.org/dp7613.pdf ;

[10] Popescu, M.E., Militaru, E., Pele, D., Mazurencu Marinescu M., Vasile, V., Ilie, S., Mihailescu, A., Serban, A. (2017), Support for Establishing a Minimum Wage-setting Mechanism in Romania. LUMEN Publishing House, http://lumenpublishing.com/index.php/lumen-books/collectivevolumes/support-for-establishing-2017/;

[11] Rani, U., Ranjbar, S. (2015), Impact of Minimum Wages on Wage Quantiles: Evidence from Developing Countries. Proceedings of the Policy Dialogue on Promoting Inclusion and Reducing Disparities in the Labor Market in Brazil and India;

[12] Vasilescu, M.D., Begu, L. (2019), Youth Reservation Wages in Romania: Are Wage Expectations Realistic? Applied economics letters, 26 (14):11571161, DOI:10.1080/13504851.2018.1540838. 